\title{
Las modulaciones de una posición "al margen". Aproximaciones a las experiencias y percepciones de los bahienses "corrientes" sobre la política y la violencia durante el tercer gobierno peronista (1973-1976)
}

\section{Modulations of a position "on the sidelines". Approaches to the experiences and perceptions of "ordinary" people of Bahía Blanca on politics and violence in the third Peronist government (1973-}

1976)

\author{
Ana Inés Seitz \\ Universidad Nacional de La Plata/Universidad Nacional del Sur \\ Consejo Nacional de Investigaciones Científicas y Técnicas, Argentina \\ anaiseitz@gmail.com
}

\begin{abstract}
Resumen
Este trabajo se enmarca en aquellas investigaciones que, en los últimos años, y dentro del campo de la Historia Reciente, procuran dar fundamento empírico a un abordaje complejo y situado de las relaciones entre sociedad civil y régimen militar. En él, nos proponemos explorar dos dimensiones centrales de la experiencia histórica de la gente "común y corriente" en Bahía Blanca durante el período 1973-1976: las de la vida política y de la violencia -en tanto noción de los propios actores-. Concretamente, abordamos sus vivencias, representaciones y evaluaciones de, por una parte, los procesos de movilización política y social, y por otra, los de avance de la violencia política revolucionaria y de la represión estatal y paraestatal. Nos proponemos examinar esta problemática desde una escala microanalítica, centrándonos en el estudio de un espacio institucional específico: la Escuela Nacional de Educación Técnica $N^{\circ} 1$ de Bahía Blanca. Nuestro objetivo es analizar los modos en que un conjunto de alumnos de la escuela en aquellos años experimentaron e interpretaron el proceso estudiantil de ocupación del colegio que tuvo lugar en junio de 1973. Ello, en el marco más amplio de sus vivencias, percepciones y lecturas sobre la política y la violencia en la ciudad durante el tercer gobierno peronista.
\end{abstract}

Palabras Clave

Historia Reciente: Activación Política; Violencia Represiva; Experiencias; Percepciones; Bahía Blanca

\footnotetext{
Abstract

This work is framed in those investigations that, in recent years, and in the field of Recent History, seek to provide empirical basis for a complex and situated approach of relations between civil society and the military regime. In it, we propose to explore two central dimensions of the historical experience of the "ordinary" people in Bahia Blanca during the period 1973-1976: the political life and the violence -as notion of the actors Esta obra está sujeta a la Licencia Reconocimiento-NoComercial-CompartirIgual 4.0 Internacional de Creative Commons. http://creativecommons.org/licenses/by-nc-sa/4.0/ (cc) EEY-NC-SA
} 


\section{Ana Inés Seitz}

themselves-. Specifically, we address their experiences, representations and evaluations, on the one hand, of the processes of political and social mobilization, and on the other, of the advance of revolutionary political violence and state and parastatal repression. We propose to examine this issue from a micro scale analysis, focusing on the study of a specific institutional space: the National School of Technical Education $\mathrm{N}^{\circ} 1$ of Bahia Blanca. We aim to analyze the ways in which a set of students in those years experienced and interpreted the process of occupation of school in June 1973. This, in the broader context of their experiences, perceptions and lectures on politics and violence in the city between 1973 and 1976.

\section{Keywords}

Recent History; Political Activation; Repressive Violence; Experiences; Perceptions; Bahía Blanca

\section{Introducción}

Si bien la problemática de las actitudes y comportamientos de la gente "común y corriente" 1 durante la última dictadura militar viene siendo tema de atención de los cientistas sociales desde los primeros tiempos de la transición democrática y ha formado parte del debate público en nuestro país como parte de las luchas por las memorias del pasado dictatorial, sólo en los últimos años ha sido abordada de manera sistemática en las investigaciones dentro del campo de estudios de la Historia Reciente ${ }^{2}$.

\footnotetext{
${ }^{1}$ La categoría de gente "común y corriente" ha sido objeto, hasta hoy, de un extenso debate sobre su contenido y alcances. Para un examen de algunas de las formas en que esta noción se ha conceptualizado en nuestro país, véase: Ana Inés Seitz: "Desafíos metodológicos en el abordaje de las actitudes sociales en dictadura (Argentina, 1976-1983). Apuntes para un campo de estudio en construcción", en: Actas de las Sextas Jornadas de Historia de la Patagonia, Neuquén, EDUCO, Universidad Nacional del Comahue, 2015. Coincidimos, en gran medida, con la definición que da Daniel Lvovich: "personas con o sin militancia política, no pertenecientes a la dirección de organizaciones políticas o sociales" (Daniel Lvovich: "Actitudes sociales y dictaduras: las historiografías española y argentina en perspectiva comparada", en: Gabriela Águila y Luciano Alonso (coord.), Procesos represivos y actitudes sociales. Entre la España franquista y las dictaduras del Cono Sur. Buenos Aires, Prometeo, 2013).

2 Véase, entre otros, los trabajos de: Mariana Caviglia, Dictadura, vida cotidiana y clases medias. Una sociedad fracturada. Buenos Aires, Prometeo, 2006; Gabriela Águila, Dictadura, represión y sociedad en Rosario, 1976/1983. Un estudio sobre la represión y los comportamientos y actitudes sociales en dictadura. Buenos Aires, Prometeo, 2008, y “Dictadura y sociedad en Rosario entre 1976 y 1983 : actitudes y comportamientos sociales en una perspectiva de análisis regional", en: Ernesto Bohoslavsky, Marina Franco, Mariana Iglesias y Daniel Lvovich (ed.), Problemas de Historia Reciente del Cono Sur. Buenos Aires, UNGS-UNSaM, 2010; Daniel Lvovich: "Sistema político y actitudes sociales en la legitimación de la dictadura militar argentina (1976-1983)", en: Ayer, № 75, Madrid, 2009, pp. 275-279; Laura Luciani: "Actitudes y comportamientos sociales durante la última dictadura militar en Argentina (1976-1983). Algunas consideraciones respecto de cómo analizar la compleja trama entre régimen y sociedad”, en: Naveg@mérica. Revista electrónica de la Asociación Española de Americanistas, 3, 2009; Sebastián Carassai, Los años setenta de la gente común. La naturalización de la violencia. Buenos Aires, Siglo XXI Editores, 2013; Mauro Greco: "Responsabilidad, resistencias y primera persona en el recuerdo de la última dictadura", en: Revista de Ciencias Sociales, segunda época, año 6, № 25, Bernal, Editorial de la Universidad Nacional de Quilmes, otoño de 2014.
} 


\section{Las modulaciones de una posición "al margen"}

En la indagación de esta cuestión, una preocupación fundamental es la de poder calibrar cuáles fueron los principales factores que motivaron y/o condicionaron las actitudes y comportamientos de la gente "común y corriente" bajo el autodenominado "Proceso de Reorganización Nacional". Sostenemos aquí que fueron muy especialmente los modos en que amplios sectores sociales vivieron y evaluaron los procesos de activación social, cultural y política, así como los ciclos de avance represivo y la situación económica y política en los años inmediatamente previos (1973-1976) los elementos que definieron, en gran medida, sus comportamientos frente al golpe militar del 24 de marzo, y a la instauración y permanencia de la dictadura ${ }^{3}$.

Dentro de este conjunto de vivencias y percepciones de dichos segmentos sociales en aquellos años, en este trabajo nos centraremos en indagar, concretamente, en las que se ligaron a la vida política y a la violencia ${ }^{4}$; ello en tanto consideramos que éstas fueron dos dimensiones centrales en sus experiencias ${ }^{5}$. Específicamente, nos interrogaremos sobre los modos en que los bahienses "corrientes" 6 vivieron e interpretaron, por un lado, la movilización política y social

\footnotetext{
3 De un modo similar en cuanto a la consideración de las formas en que las vivencias de los años previos motivaron los comportamientos sociales de la gente "corriente" bajo regímenes dictatoriales, se ha planteado -para el franquismo- que "la honda huella dejada por la experiencia de la violencia política de la guerra" fue uno de los factores -entre otros muchos- que condicionaron las actitudes sociales de los ciudadanos "de a pie" frente al régimen (Claudio Hernández Burgos, Carlos Fuertes Muñoz, Miguel Ángel del Arco Blanco y Jorge Marco: "Introducción”, en: Miguel Ángel del Arco Blanco, Carlos Fuertes Muñoz, Claudio Hernández Burgos y Jorge Marco (eds.), No sólo miedo. Actitudes políticas y opinión popular bajo la dictadura franquista (1936-1977), Granada, Ed. Comares, 2013, p. 5).

${ }^{4}$ No pretendemos en este trabajo dar una interpretación sobre la violencia en la década de los setenta, sino únicamente abordarla como una noción de los entrevistados, en la cual construyen sentidos en los que establecen una continuidad entre la violencia política revolucionaria y la represión estatal y paraestatal. Analíticamente, sin embargo, no pueden ser consideradas violencias simétricas ni equiparables.

5 Para un análisis que plantea la importancia de ambas cuestiones para el período véase: Sebastián Carassai, Los años setenta de la gente común... Op. Cit., p. 14. Marina Franco, por otra parte, ha señalado la relevancia que adquirió la dimensión de la violencia en la experiencia histórica en aquellos años, subrayando -al mismo tiempo- que ésta no fue la única, y que "no permite explicar cabalmente el período si se excluyen otras dimensiones cruciales como el profundo problema social y económico de la época y, de manera más general, el proceso de crisis y colapso del modelo populista" (Marina Franco, Un enemigo para la nación. Orden interno, violencia y subversión, 19731976. Buenos Aires, Prometeo, 2012, p. 30).

${ }^{6}$ Bahía Blanca, ubicada en la región suroeste de la provincia de Buenos Aires, en la década de los setenta no superaba los 200 mil habitantes. Se trataba, por tanto, de una localidad de dimensiones intermedias, con una población significativamente menor a la de otros centros urbanos del país, como La Plata (que por esos años duplicaba ese número), o Rosario, que alcanzaba cifras cercanas a los 800 mil habitantes (Lorena Montero "El rol de la 'comunidad informativa' en la represión en Bahía Blanca (1975-1977): prácticas, acuerdos y disputas", en: Gabriela Águila, Santiago Garaño y Pablo Scatizza (comp.), Represión estatal y violencia paraestatal en la Historia Reciente Argentina. Nuevos abordajes a 40 años del golpe de Estado. La Plata, FAHCE-UNLP, 2016, p. 370). Sin embargo, dada su ubicación geográfica estratégica -como epicentro de las comunicaciones terrestres, marítimas y aéreas entre el norte y sur de país- y su desarrollo económico -como centro industrial, comercial, financiero y de servicios-, era una ciudad con gran influencia e importancia en la región. Esta gravitación era tanto económica como política y cultural (Virginia Dominella et al: "Marcas locales de la dictadura en Bahía Blanca", ponencia presentada en: Segundo Seminario Internacional
} 


\section{Ana Inés Seitz}

-y los procesos de radicalización de determinados sectores juveniles- a fines de la dictadura de la "Revolución Argentina" y comienzos del período democrático7; y por otro, el avance de la violencia revolucionaria y de la represión paraestatal y estatal durante el tercer gobierno peronista.

Nos proponemos examinar esta problemática desde una escala microanalítica, centrándonos en el estudio de un espacio institucional específico: la Escuela Nacional de Educación Técnica N 1 "Ing. César Cipolletti" (ENET) de Bahía Blanca $^{8}$. El punto de partida de este trabajo lo constituye un hecho de movilización política y social que protagonizó la comunidad educativa de la escuela en junio de 1973: la ocupación de la institución por parte de sus alumnos, con el objetivo de desplazar a su directora del cargo. Nos proponemos analizar los modos en que un conjunto de alumnos de la escuela en aquellos años experimentaron e interpretaron este proceso de ocupación, en el marco más amplio de sus vivencias, percepciones y lecturas sobre la política y la violencia entre 1973 y 1976 en Bahía Blanca. Nuestra indagación se fundamenta en una serie de entrevistas orales semiestructuradas a estudiantes de la ENET de la década del setenta9 9

"Políticas de la Memoria": Vivir en dictadura. La vida de los argentinos entre 1976 y 1983, Buenos Aires, 2009).

${ }^{7}$ El período de análisis recortado debe ser entendido dentro de un ciclo de movilización política y protesta social que desborda esta cronología, y que se abre en 1969 con el "Cordobazo" y las subsiguientes puebladas (Maristella Svampa: "El populismo imposible y sus actores, 1973-1976", en: Daniel James (dir.), Violencia, proscripción y autoritarismo (1955-1976). Nueva Historia Argentina, T. IX. Buenos Aires, Sudamericana, 2003). Estas experiencias previas ciertamente tuvieron efectos en la configuración de las vivencias, percepciones y lecturas de los bahienses "corrientes" sobre dichos procesos políticos y sociales en los años que median entre los últimos tiempos de la dictadura de la "Revolución Argentina" y los del tercer gobierno peronista.

${ }^{8}$ La ENET No 1 fue creada con el nombre de "Escuela Industrial de Artes y Oficios de la Nación" el 6 de abril de 1937, y en junio de dicho año comenzó a funcionar en dependencias del Colegio Nacional de Bahía Blanca. Como consecuencia de la falta de un edificio propio, el constante aumento de la matrícula, y de los crecientes requerimientos de espacio adecuado a las actividades específicas que desarrollaba, la escuela sufrió sucesivos traslados. En 1938 se mudó a Parchappe 938, y en 1942, al edificio en el que antiguamente había operado la Barraca "Tellarini", ubicado en Chiclana 946. El 16 de agosto de 1977 fue inaugurado su edificio propio, en cercanías del Parque Independencia, en el que permanece hasta la actualidad. Si bien carecemos de datos específicos sobre la matrícula de cada año, hacia 19781280 estudiantes asistían al "Industrial" -nombre con el que los alumnos denominaban al colegio en esa época-. Para la misma fecha, 240 personas conformaban su equipo docente, administrativo y de maestranza ((Véase: La Nueva Provincia, Sesquicentenario de Bahía Blanca. Exposición histórica, política, social y económica de su evolución. Homenaje de "La Nueva Provincia" al cumplirse 150 años de su fundación. 1828-11 de abril-1978. Bahía Blanca, La Nueva Provincia, 1978). Si consideramos que, como señalamos anteriormente, la población de Bahía Blanca en esos años no alcanzaba los 200.000 habitantes, podemos afirmar que casi el $1 \%$ de los habitantes de la ciudad formaba parte de la comunidad educativa de la ENET. Si incluimos a las familias de los alumnos, considerando un núcleo estándar de 4 personas, dicho porcentaje asciende al 2,5\%.

9 Éstas fueron realizadas en Bahía Blanca recientemente, entre 2011 y 2015, años en los que se llevaron a cabo en la ciudad los primeros juicios por crímenes de Lesa Humanidad cometidos en el ámbito del V Cuerpo de Ejército y en el de la Base Naval Puerto Belgrano. Estas instancias judiciales instalaron con fuerza en el espacio público bahiense el debate sobre la última dictadura militar, y la década de los setenta en general; en especial, sobre lo acontecido a nivel local en dichos años.

Nuestro objetivo de reconstruir los modos en que estos estudiantes de la ENET entrevistados vivieron los ciclos de movilización política y social, así como los de violencia política revolucionaria y de represión estatal y paraestatal, no desconoce que dicho estudio está mediado por el tipo de 


\section{Militancia y radicalización política y social. Experiencias y sentidos en torno de la toma de la ENET en 1973}

En este primer apartado nuestro objetivo es abordar los modos en que la militancia y los procesos de creciente movilización social y política, y de radicalización de determinados sectores, fueron vivenciados e interpretados por los estudiantes de la ENET.

El grado en que la simpatía y la adhesión hacia las corrientes de izquierda y hacia el proceso de radicalización social y política se había extendido en amplios sectores sociales a comienzos de los años setenta, es una cuestión que ha sido objeto de debate en los últimos años en el campo de la Historia Reciente. Por una parte, algunos autores han señalado que tanto las organizaciones armadas como el recurso a la violencia política se enmarcaron en un clima de consentimiento y aceptación de parte de franjas importantes de distintos sectores políticos y sociales. Este apoyo social se habría extendido, en la perspectiva de estos investigadores, en los años que abarcan desde el Cordobazo, en 1969, hasta mediados o fines de $1973^{10}$. En particular, Tortti ha señalado que la serie de tomas que tuvo lugar en los primeros meses de aquel año constituye la culminación del ciclo de radicalización de la "Nueva Izquierda"11.

En contraposición, recientemente Sebastián Carassai ha argumentado, a partir del análisis de encuestas de opinión y de los resultados de las elecciones presidenciales de marzo de 1973, que dichos datos permiten "cuestionar la idea de que las guerrillas contaban en sus inicios con altos porcentajes de simpatía en la población y específicamente en las clases medias"12. Asimismo, este autor,

fuente en que basamos principalmente este trabajo: el análisis de memorias personales en su formalización oral. Éstas, como es sabido, no son un relato fiel de los hechos del pasado, sino que en ellas siempre tiene lugar una construcción de ese pasado, hecha desde el presente de quien relata. Por tanto, están constantemente expuestas a reelaboraciones y reinterpretaciones en tanto están atravesadas por el paso del tiempo, y entonces, por las luchas por la memoria que se dan en el espacio público, así como por los cambios en los escenarios memoriales y, más ampliamente, en los contextos culturales, sociales y políticos en que se sitúa el entrevistado. Por esta razón, hemos procurado focalizar nuestro análisis en las percepciones que se ligaban a episodios concretos vividos por los entrevistados, principalmente, a la ocupación de la ENET en 1973. Esto en tanto entendemos, en acuerdo con Jordi Font i Agulló, que "se deben tomar muchas precauciones frente a los intentos de algunos informantes de explicar una historia global que ellos no han vivido personalmente", y que "en definitiva, la historia oral es especialmente útil para captar las significaciones y las percepciones que para el informante supuso la experiencia de su propia vida" (Jordi Font i Agulló: “'Nosotros no nos cuidábamos de la política'. Fuentes orales y actitudes políticas en el franquismo. El ejemplo de una zona rural, 1939-1959”, en: Historia Social, N 49, Valencia, 2004, pp. 51).

10 Véase: María Cristina Tortti: "Protesta social y Nueva Izquierda en la Argentina del Gran Acuerdo Nacional”, en: Alfredo Pucciarelli (ed.), La primacía de la política. Lanusse, Perón y la Nueva Izquierda en tiempos del GAN. Buenos Aires, EUDEBA, 1999; Vezzetti, Hugo, Pasado y presente. Guerra, dictadura y sociedad en la Argentina. Buenos Aires, Siglo XXI Editores, 2002; Maristella Svampa: "El populismo imposible y sus actores, 1973-1976"..., Op. Cit.; Marina Franco, Un enemigo para la nación..., Op. Cit.

11 María Cristina Tortti, "Protesta social y Nueva Izquierda en la Argentina del Gran Acuerdo Nacional" ..., Op. Cit.

12 Sebastián Carassai, Los años setenta de la gente común..., Op. Cit., p. 125. 


\section{Ana Inés Seitz}

basándose en el análisis de prensa, entrevistas y programas de televisión de la época, discute la idea de que las clases medias hayan adherido al proceso de radicalización política y social durante los primeros años de la década del setenta. Carassai plantea que dicha aceptación tenía su núcleo, principalmente, en los segmentos juveniles universitarios, en tanto que la percepción de los sectores que estaban por fuera de dichos espacios institucionales se caracterizó por una actitud de ajenidad respecto de la violencia social y la militancia política ${ }^{13}$.

Un punto central de su argumento es, por tanto, el señalamiento de que la mayor parte de la actividad política de los jóvenes se centró en el espacio universitario, al que asistía sólo una minoría, que si bien tenía gran visibilidad, constituía un porcentaje reducido dentro de los sectores juveniles del país. El autor afirma que "el entusiasmo por las corrientes de izquierda, por tanto, lejos de ser mayoritario, se concentró en una franja de la población bastante específica: los jóvenes -fundamentalmente, universitarios- de 'clase media superior' y de 'clase alta'. Sin embargo, aun en esos segmentos esas simpatías fueron minoritarias"14. Asimismo, subraya que "los jóvenes universitarios, de hecho, eran una minoría social. Hacia mitad de la década del setenta, el total de los estudiantes de la Universidad de Buenos Aires representaba el 1\% de la población del país, y el de todas las universidades nacionales alcanzaba el 2\%. Estos datos ayudan a mensurar la gravitación que tenían las juventudes militantes de clase media"15.

Es en el marco de este debate que nos interesa pensar los modos en que la militancia y los procesos de radicalización política y social se expresaron en la ENET bahiense; en particular, en un episodio de conflicto y movilización como fue la toma del colegio en junio de 1973. Este hecho constituyó el principal proceso de activación política que vivió el "Industrial” en la década de los setenta, enmarcado en el ciclo de ocupaciones que se produjeron, en los inicios del gobierno de Cámpora, en numerosos y diversos espacios en todo el país -entre ellos, decenas de escuelas secundarias. La ENET fue ocupada por sus alumnos entre el 12 y el 19 de junio, con el objetivo principal -junto a otros reclamos gremiales- de reemplazar a la directora del colegio, la ingeniera Fenil Echarren. La toma contó, al menos en sus comienzos, con la participación de gran cantidad de estudiantes de los últimos años, con el aval de muchos de los profesores de la escuela, y con el acuerdo de buena parte de los padres. Luego de una sucesión de interventores que fueron proponiendo los jóvenes ${ }^{16}$ y renunciando, Héctor Herrero quedó designado definitivamente como nuevo director ${ }^{17}$.

\footnotetext{
13 Ídem, pp. 84 y 120.

14 Ídem, p. 36.

15 Ídem, p. 37.

16 Este mecanismo en el cual quienes ocupaban la entidad elegían a las nuevas autoridades fue lo usual en la mayoría de las tomas a nivel local y nacional (Véase: Flavián Nievas: "Cámpora: Primavera-Otoño. Las tomas”, en: Alfredo Pucciarelli (ed.), La primacía de la política. Lanusse, Perón y la Nueva Izquierda en tiempos del GAN. Buenos Aires, EUDEBA, 1999, p. 362).

17 Herrero era un antiguo profesor de la escuela, que contaba con la confianza de los alumnos. Para un análisis de la ocupación de la ENET, véase: Ana Inés Seitz: "Sentidos sobre la política en las
} 
En el contexto de la primavera camporista, y con este cambio de autoridades, en el colegio comenzó a haber espacio para el debate, la participación y la militancia política ${ }^{18}$. Poco antes de la ocupación de la ENET, los alumnos habían conformado una "Coordinadora"19 que, luego de este proceso, fue reconocida por las nuevas autoridades del colegio, y atendidos sus planteos y reclamos $^{20}$. Estas demandas, así como las actividades que desarrollaba esta agrupación, parecen haber estado centradas principalmente en problemas y cuestiones propias de la ENET, es decir, en reclamos gremiales. NO recuerda que "en general se hablaban de cosas relacionadas con la escuela, con el funcionamiento de la escuela. Alguna vez yo tengo idea de que se juntó plata o cosas para llevar a alguna villa, o alguna vez yo tengo idea de que hubo alguna colecta de cosas así, alimentos perecederos y eso para llevar a algún lado, que había organizado el centro de estudiantes" 21.

La "Coordinadora" estaba integrada tanto por delegados de curso que tenían distintos tipos de adscripciones políticas, como por otros que no tenían ninguna pertenencia. Sin embargo, en gran parte, "tenía participación de gente que tenía vínculo político en otro lado, pero era multipartidario [...] participaba quien quería [...] Yo lo que me acuerdo que había gente de la UES ${ }^{22}$, uno del Partido Comunista, y no sé si habría de otro lado, porque prácticamente radicales no sé si habría alguno, bueno, un par había" (JS). Sin embargo, era claro el predominio que

memorias sobre la toma de la Escuela Nacional de Educación Técnica № 1 en 1973", en: Question, vol. $1, \mathrm{~N}^{\circ} 49$, enero-marzo de 2016.

18 "Como que hubo más participación de la gente, de los profesores [...] había profesores que tenían un pensamiento político y entonces lo expresaban mucho más, como que había una apertura". (Entrevista a JS, Bahía Blanca, 3 de octubre de 2012. Ingresó a la ENET № ${ }^{\circ}$ en 1970. En adelante: JS).

${ }^{19}$ La "Coordinadora" estaba integrada por un cuerpo de delegados de cada curso de la ENET. Tenía además una comisión directiva. Es importante recordar que el 31 de mayo de 1973 el Ministerio de Educación había derogado el decreto Jorge de la Torre, que databa de 1936 y prohibía toda forma de agremiación estudiantil secundaria (Véase: Valeria Manzano: "Cultura, política y movimiento estudiantil secundario en la Argentina de la segunda mitad del siglo XX", en: Propuesta Educativa, № 35, Buenos Aires, FLACSO-Argentina, 2011).

20 "[la relación de los alumnos con los directivos] era buena, muy buena, porque la apertura que ellos tenían con respecto al centro de estudiantes [...] Se podían hacer cosas, digamos. El centro, teníamos elecciones, nos consultaban, o sea, era buena, era buena" (Entrevista a MB. Bahía Blanca, 12 de julio de 2011, realizada por Virginia Dominella. Ingresó a la ENET N¹ en 1970).

${ }^{21}$ Entrevista a NO (Bahía Blanca, 18 de agosto de 2015. Ingresa a la ENET $N^{\circ} 1$ en 1973. En adelante: NO). En el mismo sentido, JC recuerda que: "en general lo que se hacía era llevar las inquietudes de los alumnos respecto a temas de mantenimiento edilicio de la escuela, de mantenimiento de mobiliario, de forma de dar las clases, de cómo se desarrollaban las actividades en el colegio tendiendo, digamos, a que fueran más accesibles a la mayoría. Después se había empezado, en el '74, a solicitar el tema de un boleto escolar, que obviamente después cuando viene el gobierno de Isabel Perón se vuelve todo atrás, pero se había intentado pedir. Lo que no me acuerdo si se logró algo con el tema del boleto escolar. Pero se habían logrado un montón de mejoras en la parte de mantenimiento edilicio, y de mantenimiento de mobiliario. Y se había logrado también mejorar el equipamiento de los talleres y del laboratorio. Un laboratorio de física y química, que obviamente estaba equipado, como en toda institución oficial después le faltaba mantenimiento, entonces bueno, después se había mejorado desde la actividad del centro" (Entrevista a JC. Bahía Blanca, 26 de junio de 2015. Ingresa a la ENET $\mathrm{N}^{\circ} 1$ en 1972)

22 Unión de Estudiantes Secundarios. 


\section{Ana Inés Seitz}

tenía en ella la agrupación peronista: "[el centro de estudiantes] estaba hegemonizado claramente por la UES, que ganó la conducción [en 1973]” (VS ${ }^{23}$ ).

En esos años, por tanto, asistían al "Industrial" un grupo de alumnos que integraban la UES a nivel local, eran reconocidos en el colegio como militantes de esta agrupación, y constituían el grupo que mayor peso político tenía en el activismo estudiantil dentro de la escuela. VS señala que en la ENET "no había claramente agrupaciones estudiantiles, como ahora o en los ochenta; en el colegio había militantes aislados de partidos de izquierda, recuerdo algunos de la Fede ${ }^{24}$ y el PCR. No recuerdo a nadie del PRT. Había sí un grupo numeroso de la UES que actuaba como un colectivo. Sus dirigentes provenían de la Juventud Católica y del Scoutismo". En el mismo sentido, JS recuerda que en la escuela "había gente del partido comunista también, y no sé si habría de otra [agrupación] más. Pero, digamos, lo que más peso tenía ahí adentro políticamente era la UES". Si bien esta agrupación no formó parte de la ocupación de la ENET de junio de 1973 públicamente en cuanto tal, como un colectivo con intereses propios y visibles, sin embargo estos militantes participaron en la medida de manera destacada.

A pesar del proceso de avance represivo de aquellos años, las actividades y reuniones de la "Coordinadora" continuaron hasta 1975. En agosto de aquel año, dos alumnos de la escuela fueron apresados por la Policía Bonaerense, y luego condenados por infracción a la ley 20840. Como consecuencia de la detención, en esos días gran parte de los alumnos de la ENET que militaban en la UES dejaron de asistir al colegio.

Nos preguntamos, entonces, ¿cuáles fueron las percepciones de los alumnos de la ENET sobre estos ciclos de activación y militancia política y social, tanto los de dentro como aquellos que sucedían por fuera de la escuela?, y, de manera más amplia, ¿en qué modos estos procesos concretos que tuvieron lugar en la ENET, así como los modos en que los integrantes de su comunidad educativa los experimentaron e interpretaron, nos permiten indagar en sus actitudes frente a los ciclos de radicalización política y social de aquellos años?

En las entrevistas realizadas encontramos, por un lado, relatos que expresan el interés y la adhesión que existía entre los estudiantes de la escuela a las propuestas de las agrupaciones de izquierda. GK señala que en esos años "todos teníamos cierta simpatía por ciertas organizaciones, no en cuanto a la violencia pero sí en cuanto a lo que proponían como el posible mundo mejor y ciertas utopías que uno maneja cuando tiene esa edad"25. En el mismo sentido, EC remarca que "generalmente, en ese entonces, o sos socialista o te tirás para el lado de izquierda. Sí, la mayoría [de los estudiantes de la ENET que tenían participación

\footnotetext{
${ }^{23}$ Entrevista a VS. Bahía Blanca, 16 de noviembre de 2011. Ingresa a la ENET N¹ en 1971. En adelante: VS.

${ }^{24}$ Federación Juvenil Comunista.

25 Entrevista a GK. Bahía Blanca, 12 de agosto de 2015. Ingresó a la ENET № 1 en 1972. En adelante, GK.
} 


\section{Las modulaciones de una posición "al margen"}

política] eran militantes de algún partido de esos"26. Desde una perspectiva distinta, otros entrevistados se ubican en una posición al margen de las agrupaciones políticas estudiantiles y de su accionar. LV, por ejemplo, señala que "yo en política nunca participé, ni ahí [en el '73] ni después"27; o EM: "y a mí me habían elegido también de delegado en el segundo año. Y yo no podía ir porque a mí se me complicaba ir"28.

En particular, es sugerente considerar los modos en que eran percibidos y valorados los militantes políticos que asistían a la escuela. CD recuerda que "eran compañeros normalmente muy aceptados por el resto, no eran ningunos vagos sino que eran buenos estudiantes, entre los cuales me acuerdo que estaban los hermanos Paira por ejemplo. Ellos eran realmente gente apreciada dentro de los compañeros"29. En el mismo sentido, VS señala que "los militantes, la mayoría de la UES, los conocí en el '73. No había ninguno en mi curso, eran un poco más grandes que yo. Eran en general gente muy querida y respetada" (SV).

¿Cómo podemos pensar entonces, a la luz de sus interpretaciones, las actitudes de estos estudiantes frente a la militancia y los procesos de radicalización de la época? En primer lugar, es evidente que los procesos de movilización social y política que se vivieron en la ENET en aquellos años, así como la militancia de algunos de sus alumnos, ponen en cuestión el planteo de Carassai de que la activación entre los jóvenes tenía su epicentro en una minoría, la de aquellos sectores de clase media que asistían a la universidad. Este autor no tiene en cuenta que la militancia política juvenil se desarrolló también en alto grado entre los estudiantes secundarios -como así también en otros sectores sociales y espacios30. Por otra parte, la escolarización secundaria, en contraposición a lo que sucedía en la universidad, englobaba a un conjunto de jóvenes mucho más numeroso y diverso en su pertenencia social. Valeria Manzano señala el incremento que experimentó la matrícula de este nivel a partir del primer peronismo, resaltando que en 1970 abarcaba aproximadamente al 46 por ciento de los jóvenes de entre 13 y 18 años. Asimismo, la autora subraya que, en dicha expansión, no sólo ingresaron a la escuela secundaria los adolescentes que pertenecían a las clases acomodadas, sino que -en el período señalado- las ramas que más crecieron fueron la normal, la técnica y el comercial ${ }^{31}$.

\footnotetext{
${ }^{26}$ Entrevista a EC. Bahía Blanca, 14 de agosto de 2015. Ingresó a la ENET № 1 en 1968. En adelante, EC.

${ }^{27}$ Entrevista a LV. Bahía Blanca, 27 de agosto de 2015. Ingresó a la ENET ํ 1 en 1968.

${ }^{28}$ Entrevista a EM. Bahía Blanca, 28 de octubre de 2015. Ingresó a la ENET $\mathrm{N}^{\circ} 1$ en 1973. En adelante, EM.

${ }^{29}$ Entrevista a CD. Bahía Blanca, 14 de mayo de 2009. Ingresa a la ENET №1 en 1970.

30 Véase, en este sentido: Santiago Garaño y Werner Pertot, La otra juvenilia: militancia y represión en el Colegio Nacional de Buenos Aires, 1971-1986. Buenos Aires, Editorial Biblos, 2002; y Valeria Manzano "Cultura, política y movimiento estudiantil secundario en la Argentina de la segunda mitad del siglo XX", en Propuesta Educativa, № 35, Buenos Aires, FLACSO-Argentina, 2011.

31 Valeria Manzano. "Juventud y modernización sociocultural en la Argentina de los sesenta", en Desarrollo Económico, Vol. 50, No. 199, octubre-diciembre de 2010, p. 369.
} 


\section{Ana Inés Seitz}

En segundo lugar, es posible señalar que las percepciones de los entrevistados sobre las organizaciones de izquierda, la militancia y la movilización política y social eran complejas y, en gran medida, ambivalentes. Encontramos que no hay entre estos ex alumnos un rechazo hacia estas cuestiones. Más aún, incluso en el caso de quienes en sus relatos se ubican en una posición de marginalidad, sus actitudes no eran de indiferencia, ni de oposición a los modos en que estas dimensiones se expresaban en la ENET. Por el contrario, tenían un interés en lo que, en ese sentido, sucedía en la escuela. Sin embargo, éste no se tradujo en su incorporación a algún tipo de militancia política, dentro o fuera del colegio.

Esta ambivalencia de gran parte de los estudiantes de la ENET se manifiesta en el desarrollo de un conjunto de actitudes que no fueron ni de adhesión total a las propuestas y acciones de las corrientes de izquierda, ni de ajenidad u oposición y rechazo. Específicamente, esta complejidad y mixtura que señalamos en sus conductas, quedó expresada en el proceso de ocupación de la ENET en junio de 1973. Es preciso tener en cuenta el tipo de medida que estos estudiantes resolvieron llevar adelante. Como señala Nievas, "una toma es siempre un hecho que vulnera la legalidad"32. Aquí los estudiantes decidieron ocupar el colegio, suspender las clases, expulsar a sus directores y, además, elegir unos nuevos. La toma, fue, por tanto, una medida de un carácter político trascendental, de impugnación, en última instancia, del orden social. Y además, se produjo en un contexto nacional específico, de amplia movilización y sucesión de ocupaciones en todo el país ${ }^{33}$. Por tanto, los alumnos que participaron, incluidos aquellos que no tenían militancia política, se sumaron a un proceso que era notoriamente disruptivo, tanto dentro de la cotidianeidad de la escuela, como a nivel nacional.

Lo paradójico para quienes fueron parte de este episodio de activación política dentro del "Industrial", fue que una de las preocupaciones de los alumnos protagonistas de la medida -contemporáneamente a los hechos- fue la de remarcar que no había motivaciones político partidarias de ningún tipo ni injerencias políticas externas que hubieran dado origen a las razones por las que se había ocupado el colegio ${ }^{34}$. Algunos de los ex alumnos fundamentan hoy su participación en la medida señalando que los reclamos eran exclusivamente gremiales, limitados a la comunidad educativa de la escuela y no derivados de intereses o conflictos políticos ajenos a este espacio. Otros, plantean que tal caracterización de la toma tenía como finalidad generar el mayor grado de adhesión posible a la medida entre los estudiantes de la ENET. Por tanto, es evidente que lo político partidario tenía

\footnotetext{
32 Flavián Nievas. “Cámpora: Primavera-Otoño. Las tomas”..., Op. Cit., p. 358.

33 Al respecto Maristella Svampa ha señalado que "la movilización alcanzó picos de verdadera insurrección: así, entre el 4 y 15 de junio se produjeron casi 500 tomas de distinto tipo en todo el país" (Maristella Svampa. “El populismo imposible y sus actores, 1973-1976”..., Op. Cit.)

34 Esta preocupación de los estudiantes quedó registrada en el periódico local, La Nueva Provincia (LNP), donde se señalaba que: "Alumnos que mantienen la ocupación de la Escuela Industrial número 1 ... manifestaron, además, que el movimiento de ocupación rechaza toda injerencia política", "Los alumnos, consultados por 'La Nueva Provincia', negaron que la ocupación tenga matiz político alguno" (LNP, Bahía Blanca, 16/06/1973)
} 


\section{Las modulaciones de una posición "al margen"}

entre estos alumnos entrevistados -y entre gran parte de los que participaron en la medida-, de alguna manera, un sentido negativo ${ }^{35}$.

La paradoja, por tanto, radica en la intervención, por parte de estos alumnos, en un hecho eminentemente político, y estrechamente ligado a la radicalización social del momento -incluso, a uno de sus momentos más álgidos-; argumentando al mismo tiempo que la medida no tenía ningún cariz político, y que se trataban sólo de demandas gremiales ${ }^{36}$. Sin embargo, no se trata de un comportamiento paradójico, sino más bien, de uno que expresa la ambivalencia que, como hemos señalado, encontramos en las actitudes hacia la militancia y la radicalización políticas de parte de estos actores.

Podemos señalar, por tanto, que encontramos en las percepciones y conductas de estos jóvenes entrevistados hacia el ciclo de movilización política y social, hacia la militancia y hacia las organizaciones de izquierda en aquellos años, un conjunto de actitudes que no eran de adhesión total, pero tampoco de rechazo y oposición, ni de indiferencia. Por el contrario, podríamos ubicar sus comportamientos en un espectro entre la aceptación y el interés -e incluso en algunos la simpatía-, y, por otro lado, cierto distanciamiento, procurando "mantenerse al margen". Si pensamos concretamente en la toma de la escuela, y específicamente en la estrategia de insistir en su carácter apolítico para concitar el apoyo y la participación de gran parte de la comunidad educativa, consideramos que estas actitudes pueden ser, de alguna manera, pensadas para todos los miembros de la comunidad educativa de la ENET que participaron en, o adhirieron a y apoyaron, la medida.

\section{Entre "los Bustos" y "los Ponce". Lecturas de la violencia política revolucionaria y de la represión estatal y paraestatal en Bahía Blanca}

En este apartado nos proponemos explorar otra de las dimensiones que consideramos fundamentales en la experiencia histórica de la gente "común y corriente" durante la década del setenta. Ésta se liga a los modos en que este sector de la sociedad experimentó y construyó sentidos sobre la violencia política revolucionaria y la represión estatal y paraestatal que se desplegó en los años del tercer gobierno peronista.

\footnotetext{
35 Sentido que, evidentemente, está atravesado por la lectura que, de esos años, hacen en el presente (al respecto véase: Ana Inés Seitz: "Sentidos sobre la política en las memorias sobre la toma de la Escuela Nacional de Educación Técnica $N^{\circ} 1$ en 1973 ”..., Op. Cit). Sin embargo, la preocupación contemporánea por caracterizar a la toma de esa manera nos permite pensar que lo político-partidario también tenía, en alguna medida, un sentido negativo en aquellos años para los integrantes de la comunidad educativa de la escuela. $\mathrm{O}$ al menos, que era una dimensión de la vida social de la que muchos querían mantenerse al margen.

${ }^{36}$ Sin embargo, los conflictos políticos de la época, en especial, aquellos que se daban entre facciones antagónicas dentro del peronismo, de distintas maneras atravesaron el proceso de ocupación de la ENET (véase: Ana Inés Seitz. "Sentidos sobre la política en las memorias sobre la toma de la Escuela Nacional de Educación Técnica N 1 en 1973”..., Op. Cit)
} 


\section{Ana Inés Seitz}

En los relatos de los ex estudiantes de la ENET entrevistados encontramos, por una parte, una lectura de los hechos de violencia en la que subrayan, actualmente, las dificultades que tenían en aquellos años para reconocer quiénes eran los protagonistas y responsables de dichos sucesos. GK recuerda que "los grupos Montoneros, cuando [Perón] los echa de la plaza, se le vuelve ingobernable, y ya, digamos, se inicia una etapa de, por un lado la Triple A de López Rega, y por el otro lado los amigos de Montoneros, ERP y demás, y una época de violencia que vos no sabías, por ejemplo, Rucci hoy no se sabe quién lo mató". También, NO señala que "la militancia en esa época era dura porque si no estaba la Triple A, estaba Montoneros o el ERP. Era difícil. Había muchas muertes que nadie sabía de dónde venían".

No obstante, en el análisis de los episodios vividos en el ámbito local, se revelan otras dimensiones de dicha construcción de sentidos en la época sobre los episodios de violencia, por parte de estos estudiantes. Nos referimos al hecho de que, aunque éstos pueden diferenciar a los principales protagonistas de dichos sucesos a nivel nacional (como la "Triple A", las Fuerzas Armadas, Montoneros, ERP); sin embargo en el espacio local, y en los acontecimientos concretos que experimentaron, tienen dificultades para reconocer quiénes eran los actores, en el sentido de identificar con qué sectores políticos del país se vinculaban. Asimismo, tampoco pueden diferenciar concretamente cuáles eran las cuestiones en disputa entre dichos grupos.

Esto nos permite pensar que la distinción clara de los actores a nivel nacional, se enmarca en lo que circulaba en los discursos públicos contemporáneos, $\mathrm{y}$, en especial, en lo que los entrevistados conocieron posteriormente, particularmente a partir de 1983 (es decir, en el marco de los relatos que sobre la dictadura y la década de los setentas se articularon a partir de esos años). Sin embargo, a nivel local, frente a la ausencia de un relato colectivo similar que diferencie a los actores políticos de Bahía Blanca, las narraciones de los entrevistados ponen de manifiesto las dificultades que tenían en la época, y que continúan hasta hoy, para reconocer los espacios políticos, las demandas específicas, y las razones concretas de los conflictos y enfrentamientos de cada uno de estos actores.

Ello se hace evidente en el caso de EC, quien recuerda un episodio de violencia durante una asamblea estudiantil en 1975 en la Facultad Regional Bahía Blanca de la Universidad Tecnológica Nacional (UTN): "viví eso que nos bajaron del quinto piso y pegándoles culatazos a los más grandes a la pasada. Acá se hablaba de que eran la gente de Ponce, era como que la tenían intervenida [a la UTN], lo tengo medio confuso, porque no sé si estaba la parte de la derecha de los militares, o eran de los subversivos". En este caso, EC no puede diferenciar en qué espacio político se ubicaban los actores de este episodio, tanto los estudiantes que realizaban la asamblea, como quienes se hacen presentes para expulsarlos de la universidad. 


\section{Las modulaciones de una posición "al margen"}

Además, y en particular, este ejemplo nos revela una cuestión relevante que podemos rastrear en las construcciones de sentido de parte de estos estudiantes de la ENET sobre los episodios de violencia ocurridos en Bahía Blanca en aquellos años. Se trata de la equiparación entre "los Bustos" y la "gente de Ponce" (o simplemente "los Ponce"), dos grupos de actores que en la década de los setenta eran muy conocidos por la sociedad local. A pesar de que se ubicaban en espacios políticos distintos, opuestos y enfrentados, varios episodios de violencia ocurridos en la ciudad en dicho período son atribuidos indistintamente a estos dos grupos, homologándolos.

Los Bustos conformaban una familia de nueve hermanos que en la década de 1950 se había radicado en Bahía Blanca. Integraban la Juventud Peronista, y paulatinamente fueron ganando peso en distintos sindicatos de la rama de la construcción y en diversas organizaciones dentro del movimiento peronista. En 1973 algunos de sus miembros accedieron a puestos en los órganos deliberativos del gobierno local y nacional ${ }^{37}$. Por su parte, Rodolfo Ponce era un dirigente sindical que ejercía como Secretario General de la Central General de Trabajadores (CGT) local e integraba la mesa nacional de las 62 organizaciones. En 1973 fue elegido como Diputado Nacional por el Frente Justicialista de Liberación. Zapata señala que Ponce "era un peronista ortodoxo que hacía oír su fuerte repudio hacia los 'extremistas' o 'izquierdistas' que 'se disfrazan de peronistas' - haciendo alusión a los militantes del PRT-ERP, Montoneros y distintas ramas de la Tendencia peronista"38. Cuando los entrevistados refieren a "los Ponce", aluden tanto al Delegado Regional de la CGT local como al personal de seguridad que lo custodiaba.

Esta equiparación entre "los Bustos" y "la gente de Ponce" es visible, concretamente, en los relatos de los estudiantes entrevistados que recuerdan los intentos, de parte de actores externos, de "apropiarse" de la toma de la ENET de junio de 1973. Durante la ocupación de la escuela, se acercaron militantes locales de la Juventud Peronista que, en Bahía Blanca, se nucleaban en torno de los hermanos Bustos. El objetivo era, probablemente, poner fin a la ocupación ${ }^{39}$. Sin embargo, en sus relatos varios ex alumnos señalan que quienes se acercaron fueron "los Ponce", en tanto otros afirman que se trataba de estos últimos junto a "los Bustos". Por ejemplo, EM señala "cuando vinieron los... que estaban los Bustos, los Ponce".

\footnotetext{
37 Véase: Ana Belén Zapata, Andamios de experiencias. Conflictividad obrera, vigilancia y represión en Argentina. Bahía Blanca, 1966-1976. Tesis doctoral. La Plata, FAHCE-UNLP, 2014.

38 Ídem, pp. 136-137.

39 Nievas señala que cuando las tomas comenzaron a extenderse y multiplicarse en diversos ámbitos, "dirigentes de la Tendencia recorrieron varios lugares 'serenando los ánimos' y pidiendo que se levantaran las tomas a la brevedad. Probablemente, lo hayan hecho urgidos frente al inminente regreso de Perón, ante quienes querían mostrase fuertes pero disciplinados" (Flavián Nievas. "Cámpora: Primavera-Otoño. Las tomas", en Alfredo Pucciarelli (ed.), La primacía de la política..., Op. Cit., p. 369).
} 


\section{Ana Inés Seitz}

Evidentemente, esta equiparación entre dos grupos de actores tan opuestos en su pertenencia política obedece a razones que son variadas y complejas. Como señalamos anteriormente, el trabajo de la memoria, especialmente post '83, tiene un papel relevante en esta homologación. Sin embargo, consideramos que en ella también jugaron un rol importante otros elementos propios de la construcción contemporánea de sentidos sobre la violencia durante el tercer gobierno peronista.

En este sentido, es relevante considerar el planteo que hace Franco, quien señala los modos en que los periódicos de la época en particular, y los discursos públicos de distintos actores sociales en general, tendieron a una condena de la violencia cada vez más "ritualizada, banalizada y con ribetes cada vez más violentos"40, la cual, hacia 1975, ya aparecía en la prensa "desprovista de todo anclaje explicativo o político y se limitaba a la enumeración de bombas, secuestros y asesinatos como único fin aparente de la información"41.

Es posible pensar, entonces, que en el marco de esta construcción de "una realidad específica, el 'imperio de la violencia"'42, estos alumnos de la ENET entrevistados contaron con pocas herramientas para dar sentido a los episodios de violencia que conocían a nivel local, así como para distinguir a sus actores, sus posicionamientos, las razones de los conflictos políticos y sociales, y de los enfrentamientos. En este contexto, tendieron a una producir una homologación de los hechos que tenían lugar en la ciudad y en el país, como parte de un "todo indiferenciado". Y es en el contexto de esta carencia de herramientas para analizar y comprender la conflictividad política de la época, en especial a nivel local, que podemos pensar la equiparación de estos alumnos de la ENET entre dos grupos de actores opuestos, y enfrentados, como eran "los Bustos" y "la gente de Ponce".

Por otra parte, en el análisis de las actitudes de la gente "común y corriente" hacia el golpe militar de 1976 y el régimen dictatorial que se instala como consecuencia, es fundamental considerar los efectos que tuvo en ellas una construcción de sentidos sobre la violencia en la que los responsables de los hechos de represión no podían ser dilucidados con claridad. Como señalan algunos entrevistados, en los primeros tiempos del "Proceso de Reorganización Nacional" atribuían los episodios que llegaban a conocer, principalmente las detenciones ilegales, las desapariciones y los asesinatos, al accionar de grupos represivos paraestatales, que, en su evaluación, se prolongaba en esos primeros meses de dictadura, en tanto aún no habían podido ser "controlados" por las Fuerzas Armadas.

Otros estudiantes, por otra parte, afirman que en aquellos años no podían deslindar cuál de estos dos grupos de actores era el responsable de los hechos represivos de los que estaban al tanto. Un ejemplo en este sentido -si bien se trata

\footnotetext{
40 Marina Franco, Un enemigo para la nación..., Op. Cit., p. 200

41 Ídem, p. 198.

${ }^{42}$ Ibídem. Más adelante, la autora también señala que "la acumulación discursiva analizada para los años 1973-1976 se produjo mediante un enmascaramiento progresivo de los intensos procesos de conflictividad política de la época que se ocultaban cada vez más bajo una totalidad vacía y atemorizante: 'la violencia'” (ídem, p. 294).
} 


\section{Las modulaciones de una posición "al margen"}

del relato de un profesor de la escuela y no de un alumno- es el recuerdo de $\mathrm{BA}^{43}$, quien, inscribiendo su narración en lo que sucedía en Bahía Blanca en el año 1976, señala:

Lo que pasa es que era terrible, porque no es solamente que estaban los grupos de tareas de las Fuerzas Armadas. Estaban las Tres A también. Y entonces vos, ya era una cosa que uno no sabía. Además los matones de las Tres A andaban por acá con los Torino y con los Falcon, con ametralladoras y escopetas Itacas, a la vista de todo el mundo [...] Y vos nunca sabías quién era. No sabías si eran las Fuerzas Armadas, si eran las Tres A, si... Después se empezó a saber, ¿no es cierto? Por supuesto. Pero al principio no.

Por tanto, en la interpretación de los sucesos de violencia a nivel local protagonizados por las Fuerzas Armadas, y aquellos otros donde los responsables eran grupos paraestatales, encontramos que los alumnos de la ENET entrevistados, si bien podían identificar y diferenciar a estos actores, en la práctica no podían distinguir quiénes eran los autores de los episodios represivos que llegaban a conocer. Más aún, en su evaluación de las características del régimen dictatorial que acababa de instalarse en el país, los eventos de violencia no eran atribuidos a los actores militares. De esta manera, las Fuerzas Armadas quedaban al margen de estos, excepto en su capacidad de controlar a sus agentes. Se trata por lo tanto de un factor que, evidentemente, pudo haber motivado en amplios sectores sociales actitudes de consentimiento hacia el régimen militar recientemente instalado. Al menos hasta que estos sectores pudieron reconocer, a partir de un saber que igualmente era fragmentado, que las propias Fuerzas Armadas eran las responsables de estos hechos de represión.

\section{Algunas reflexiones finales}

Como punto de partida de este trabajo, sosteníamos que las experiencias de la gente "común y corriente" durante el tercer gobierno peronista, así como sus percepciones e interpretaciones de los procesos sociales y políticos vividos desde fines de la década de los sesenta y en particular en dicho período democrático, condicionaron de forma singular sus comportamientos frente al quiebre institucional del 24 de marzo de 1976, y a la instauración del régimen dictatorial. En este marco, y a través del análisis de lo que aconteció en esos años democráticos en la ENET $N^{\circ} 1$ de Bahía Blanca, nuestro objetivo fue realizar una primera aproximación a dos dimensiones centrales dentro de la experiencia histórica de los estudiantes del colegio durante la década de los setenta; una de ellas referida a sus vivencias, representaciones y juicios sobre la militancia y los procesos de radicalización política y social de dichos años; en tanto que la otra,

${ }^{43}$ Entrevista a BA. Bahía Blanca, 20 de octubre de 2015. Profesor de la ENET $N^{\circ} 1$. 


\section{Ana Inés Seitz}

centrada en sus experiencias y valoraciones sobre la violencia política revolucionaria y la represión estatal y paraestatal que se desplegó en el período.

A modo de reflexión final, entonces, nos proponemos explorar sintéticamente la pregunta acerca de los modos en que estas vivencias y lecturas de los años democráticos previos al golpe de Estado pudieron haber motivado las actitudes y comportamientos de los estudiantes entrevistados frente al quiebre institucional y durante los años de dictadura.

En cuanto a la segunda dimensión analizada, como señalamos, siguiendo a Franco, los modos en que los discursos políticos y la prensa en general presentaban la conflictividad política, sustituyendo "todo análisis y explicación [de la misma] por categorías esencializantes y vacías" 44 , nos permiten pensar en la forma en que, en las lecturas de los alumnos de la ENET sobre la violencia, se dificultaba la diferenciación de los responsables de este tipo de hechos, sus espacios políticos y sus principales líneas de confrontación. ¿Cuáles fueron algunos de los efectos de esta construcción de sentidos sobre la violencia?

Franco señala que a través de estos discursos políticos y periodísticos se generó en la sociedad un "miedo al 'caos' y a la 'violencia' -y en particular a la subversión- que hizo del recurso a las Fuerzas Armadas una garantía de 'solución' y 'orden', a la vez que permitió aceptar como necesaria la escalada represiva y la supresión de libertades"45. Esta lectura, se fusionó con una construcción de sentidos sobre la violencia de parte de los estudiantes entrevistados, en la que, al menos durante los primeros tiempos del régimen, los actores militares quedaban al margen de los episodios represivos.

De este modo, una interpretación en la que el actor militar aparecía como el adecuado para retornar al "orden" y la "normalidad", se fusionó con otra en la que las Fuerzas Armadas no eran responsables de los episodios represivos, sino, por el contrario, quienes debían poner freno a estos hechos. Así, esta lectura ciertamente fue uno de los factores que pudo haber configurado cierto grado de consentimiento de parte de los alumnos del "Industrial", tanto hacia el golpe militar como hacia el régimen que se instauró como consecuencia.

En cuanto a la primera dimensión de análisis, podemos considerar que hubo un pasaje desde unas actitudes ambiguas de parte de los jóvenes estudiantes de la ENET hacia la militancia de izquierda y los ciclos de radicalización política y social de principios del tercer gobierno peronista, hacia otras caracterizadas por el rechazo de este tipo de participación y de este tipo de procesos, trayectoria que probablemente haya tenido lugar a lo largo de 1974 y 1975. Sin embargo, aún desde esta posición de ajenidad respecto de la militancia política, debemos notar el peso los lazos de compañerismo, y de cercanía y cotidianeidad, siguieron teniendo en la percepción de aquellos militantes que no eran parte de una noción "abstracta" percibida a través de los medios periodísticos y los discursos políticos, sino de la vida escolar diaria de los estudiantes de la ENET. Estos lazos de

44Marina Franco, Un enemigo para la nación..., p. 281.

45 Ídem, p. 280. 


\section{Las modulaciones de una posición "al margen"}

solidaridad conformados a través de la cotidianeidad crearon un vínculo que atravesó la estigmatización de estos militantes. Queda entonces, como una pregunta abierta para futuras indagaciones, la consideración de los modos en que las actitudes ambiguas y complejas, en especial hacia la participación política de izquierda de parte de estos jóvenes estudiantes de la ENET a principios del tercer gobierno peronista, se combinaron con estas otras percepciones positivas sobre sus compañeros militantes, y de qué modo influyeron en la conformación de las actitudes de estos jóvenes hacia la dictadura militar instaurada en 1976.

\section{Bibliografía}

Ana Belén Zapata. Andamios de experiencias. Conflictividad obrera, vigilancia y represión en Argentina. Bahía Blanca, 1966-1976. Tesis doctoral. La Plata, FAHCE-UNLP, 2014.

Ana Inés Seitz. "Desafíos metodológicos en el abordaje de las actitudes sociales en dictadura (Argentina, 1976-1983). Apuntes para un campo de estudio en construcción" en Actas de las Sextas Jornadas de Historia de la Patagonia, Neuquén, EDUCO, Universidad Nacional del Comahue, 2015.

Ana Inés Seitz. "Sentidos sobre la política en las memorias sobre la toma de la Escuela Nacional de Educación Técnica $N^{\circ} 1$ en 1973” en Question, vol. 1, N 49, enero-marzo de 2016.

Daniel Lvovich. "Actitudes sociales y dictaduras: las historiografías española y argentina en perspectiva comparada" en Gabriela Águila y Luciano Alonso (coord.), Procesos represivos y actitudes sociales. Entre la España franquista y las dictaduras del Cono Sur. Buenos Aires, Prometeo ,2013.

Daniel Lvovich. "Sistema político y actitudes sociales en la legitimación de la dictadura militar argentina (1976-1983)”, Ayer, № 75, 2009.

Flavián Nievas. "Cámpora: Primavera-Otoño. Las tomas” EN Alfredo Pucciarelli, (ed.), La primacía de la política. Lanusse, Perón y la Nueva Izquierda en tiempos del GAN, Buenos Aires, EUDEBA, 1999.

Gabriela Águila. "Dictadura y sociedad en Rosario entre 1976 y 1983: actitudes y comportamientos sociales en una perspectiva de análisis regional" en Ernesto Bohoslavsky, Marina Franco, Mariana Iglesias y Daniel Lvovich (ed.), Problemas de Historia Reciente del Cono Sur. Buenos Aires, UNGS-UNSaM, 2010.

Gabriela Águila. Dictadura, represión y sociedad en Rosario, 1976/1983. Un estudio sobre la represión y los comportamientos y actitudes sociales en dictadura. Buenos Aires, Prometeo, 2008.

Hugo Vezzetti. Pasado y presente. Guerra, dictadura y sociedad en la Argentina. Buenos Aires, Siglo XXI Editores, 2002.

Jordi Font i Agulló. “'Nosotros no nos cuidábamos de la política'. Fuentes orales y actitudes políticas en el franquismo. El ejemplo de una zona rural, 1939-1959", en Historia Social, N 49, Valencia, 2004. 


\section{Ana Inés Seitz}

La Nueva Provincia Sesquicentenario de Bahía Blanca. Exposición histórica, política, social y económica de su evolución. Homenaje de "La Nueva Provincia" al cumplirse 150 años de su fundación. 1828-11 de abril-1978. Bahía Blanca, La Nueva Provincia, 1978.

Laura Luciani. “Actitudes y comportamientos sociales durante la última dictadura militar en Argentina (1976-1983). Algunas consideraciones respecto de cómo analizar la compleja trama entre régimen y sociedad" en Naveg@mérica. Revista electrónica de la Asociación Española de Americanistas, 2009.

Lorena Montero. “El rol de la 'comunidad informativa' en la represión en Bahía Blanca (1975-1977): prácticas, acuerdos y disputas”, en Gabriela Águila, Santiago Garaño y Pablo Scatizza (comp.), Represión estatal y violencia paraestatal en la Historia Reciente Argentina. Nuevos abordajes a 40 años del golpe de Estado. La Plata, FAHCE-UNLP, 2016.

María Cristina Tortti. "Protesta social y Nueva Izquierda en la Argentina del Gran Acuerdo Nacional" en Alfredo Pucciarelli (ed.), La primacía de la política. Lanusse, Perón y la Nueva Izquierda en tiempos del GAN. Buenos Aires, EUDEBA, 1999.

Mariana Caviglia. Dictadura, vida cotidiana y clases medias. Una sociedad fracturada. Buenos Aires, Prometeo, 2016.

Marina Franco. Un enemigo para la nación. Orden interno, violencia y subversión, 1973-1976. Buenos Aires, Prometeo, 2012.

Maristella Svampa. "El populismo imposible y sus actores, 1973-1976" en Daniel James (dir.), Violencia, proscripción y autoritarismo (1955-1976). Nueva Historia Argentina, T. IX. Buenos Aires, Sudamericana, 2003.

Mauro Greco. "Responsabilidad, resistencias y primera persona en el recuerdo de la última dictadura" en Revista de Ciencias Sociales, segunda época, año 6, № 25, Bernal, Editorial de la Universidad Nacional de Quilmes, otoño de 2014.

Miguel Ángel Del Arco Blanco, Carlos Fuertes Muñoz, Claudio Hernández Burgos y Jorge Marco (eds.), No sólo miedo. Actitudes políticas y opinión popular bajo la dictadura franquista (1936-1977), Granada, Ed. Comares, 2013.

Santiago Garaño y Pertot Werner. La otra juvenilia: militancia y represión en el Colegio Nacional de Buenos Aires, 1971-1986. Buenos Aires, Editorial Biblos, 2002.

Sebastián Carassai. Los años setenta de la gente común. La naturalización de la violencia. Buenos Aires, Siglo XXI Editores, 2013.

Valeria Manzano. "Cultura, política y movimiento estudiantil secundario en la Argentina de la segunda mitad del siglo XX", en Propuesta Educativa, № 35, Buenos Aires, FLACSO-Argentina, 2011.

Valeria Manzano. "Juventud y modernización sociocultural en la Argentina de los sesenta" en Desarrollo Económico, Vol. 50, No. 199, octubre-diciembre de 2010.

Virginia Dominella, Florencia Fernández Albanesi, María Lorena Montero, Andrea Rodríguez, Ana Inés Seitz, Ana María Vidal y Ana Belén Zapata, “Marcas locales de la dictadura en Bahía Blanca", ponencia presentada en Segundo Seminario 
Las modulaciones de una posición "al margen"

Internacional "Políticas de la Memoria": 'Vivir en dictadura. La vida de los argentinos entre 1976 y 1983', Buenos Aires, 2009.

Recibido: $14 / 05 / 2016$

Evaluado: $18 / 06 / 2016$

Versión Final: 01/08/2016 